\title{
Disputas pelo monopólio da prática odontológica e a criação da Escola Livre de Odontologia do Pará (1911-1914)
}

Disputes by monopoly practice dentistry and the creation of the free school of dentistry of Pará (1911-1914)

\author{
Marcelino Carmo de Lima $^{1}$ \\ Sulenir Cândida da Silva Nascimento ${ }^{2}$ \\ Jerônimo Alves $^{3}$
}

\section{Resumo}

O objetivo desta pesquisa é analisar os jornais publicados no Estado do Pará, no período que antecedeu a criação, em 1914, da Escola Livre de Odontologia do Pará, quando a odontologia ainda era praticada tanto por profissionais formados em escolas situadas fora do Estado como pelos era que não tinham escolaridade. Constatamos que os jornais, Estado do Pará e A Província do Pará, no período que antecedeu a criação da Escola, ou seja, de 1911 a 1914 publicaram várias notícias relacionadas à formação e a prática da odontologia. Quais foram essas notícias? Constatamos que elas manifestaram, sobretudo, as polêmicas entre os portadores de diplomas obtidos nas escolas de odontologia fora do Estado que pretendiam excluir os demais chamados pejorativamente de "sacamuelas". As reivindicações sobre o monopólio da profissão, portanto, como mostra o noticiário, iniciaram antes mesmo da criação da Escola do Pará.

Palavras chave: história da ciência; odontologia; Pará.

\section{Abstract}

The objective of this research is to analyze the newspapers published in the State of Pará, in the period that preceded the creation, in 1914, of the Escola Livre de Odontologia do Pará, when dentistry was still practiced both by professionals trained in schools located outside the State and by the others. We find that the newspapers, the Estado do Pará and A Província do Pará, in the period before the creation of the Escola that is, from 1911 to 1914 published several news related to the formation and practice of dentistry. What was this news? We found that they expressed, above all, the controversies among the holders of diplomas obtained in schools of dentistry outside the State that sought to exclude the others. The claims about the monopoly of the profession, therefore, as the news shows, began even before the creation of the Escola do Pará.

Keywords: history of science; dentistry; Pará.

\footnotetext{
${ }^{1}$ marcelinolima.msc@gmail.com

2 sule.mtb@gmail.com

3 jeronimoalves@hotmail.com
} 


\section{Introdução}

O modo como funcionam as áreas de saúde nos dias de hoje é consequência de um processo histórico, que longe de ter se desenvolvido de modo contínuo e apaziguado resultou de disputas e conflitos. Um dos acontecimentos que mais tem despertado a atenção dos historiadores se caracteriza pela querela entre os profissionais que passaram a ser formados pelas faculdades ou escolas de medicina quando estas foram criadas e os que ingressaram na profissão de outro modo, tal como, pela aprendizagem com os mais experientes. Essa mudança no processo de profissionalização e, ao mesmo tempo, da institucionalização na área da saúde, tem sido explorada, sobretudo no campo da medicina. A análise dessa mudança tem sido realizada em vários momentos da história e em vários espaços geográficos (EDLER, 2011). No campo da odontologia, embora essas investigações sejam menos intensas, já começaram a ser realizadas, como veremos nos exemplos que seguem.

Cristiana Leite Carvalho (2006), no artigo, A transformação no mercado de serviços odontológicos e as disputas pelo monopólio da prática odontológica no século XIX, resgatou os fatores que contribuíram para a profissionalização da odontologia, nos Estados Unidos, onde esta teria surgido como profissão moderna e desvinculada da medicina ${ }^{4}$. A inclusão das disputas entre os diversos praticantes da arte dentária pelo exercício da prática odontológica é destacada no próprio título do artigo, em que ela mostra que essas disputas modificaram a prática odontológica pela criação de uma legislação específica regulando a profissão e o mercado de serviços desse campo de trabalho.

Essas disputas também foram analisadas por Schapira (2003) ao incidir sobre o processo de profissionalização da odontologia, na Argentina, no período que se estende do final do século XIX à primeira metade do século XX. Ela analisou os conflitos entre os cirurgiões dentistas e outros profissionais, como os médicos, os dentistas práticos e as estratégias que eles empreenderam para obter o apoio do Estado no monopólio do exercício da profissão, pelos formados nas universidades.

A mudança no processo de profissionalização, com a criação das Faculdades, não ocorreu exclusivamente nos Estados Unidos, na Argentina ou em outro lugar específico. Trata-se de um processo em que práticas tradicionais passaram a ser questionadas pela dinâmica da modernidade, onde esta se fazia presente.

A Escola Livre de Odontologia do Pará foi implantada na Amazônia, em 1914, logo após o período denominado de Belle-Époque, que abrangeu as últimas décadas do século anterior e primeira do século seguinte. A penetração da modernidade, acelerada nesse período, nos centros mais urbanizados dessa região, tem sido bastante assinalada pelos historiadores (DAOU, 2000, SARGES, 2000). Conforme enfatizam, com os lucros obtidos pela exportação do látex, as cidades, sobretudo, Belém e Manaus, foram radicalmente

\footnotetext{
${ }^{4}$ Conforme Gies (1926, p. 39-40), por volta de 1840, nos EUA, fundou-se a primeira escola de odontologia como um sistema separado da medicina. Quando se estabeleceu que o ensino em odontologia não poderia ser desenvolvido sob os auspícios médicos ou em associação com a medicina, a alternativa foi estabelecer uma escola dentária independente e o desenvolvimento da educação formal em odontologia como um sistema autônomo. A primeira Escola de Odontologia foi denominada Baltimore College of Dental Surgery, localizada em Baltimore no EUA, fundada em 1840.
} 
transformadas, inspiradas nos modelos de urbanização em vigor nas modernas cidades da Europa, sobretudo Paris. Profissionais de saúde formados em escolas destinadas exclusivamente com esse objetivo, uma das exigências desse modelo, começaram a atuar no Pará, mesmo antes da criação da Escola e a lutar pelo monopólio da profissão.

Silvio Rodrigues (2010), no artigo Senhores da cura: negociações e conflitos no diversificado universo da cura no extremo norte do Brasil, 1889-1919, como o próprio título sugere, se reporta, sobretudo, ao campo da medicina. Ele assinala que, no Pará, entre o final do século XIX e a segunda década do século XX, os profissionais da saúde, sobretudo, médicos participaram de um movimento cuja finalidade era se unir em busca de um interesse comum: pressionar o Estado no sentido de reprimir os praticantes de outras formas de cura, consideradas ilegais. (RODRIGUES, 2010, p. 6).

O historiador Aldrin Figueiredo (2006) também se refere a esses embates. Segundo esse autor, os profissionais do campo da saúde que atuavam em Belém no inicio do século $X X$, sobretudo os médicos, buscavam o reconhecimento de suas práticas em meio à população, que a essa altura, procurava mais os curandeiros, que os próprios representantes da medicina oficial. Ele afirma que os esculápios paraenses se empenhavam para se constituir e se solidificar como "classe" e "organismo social". Para isso, faziam uso das armas que dispunham, como a imprensa, onde divulgavam a solução dos problemas sanitários existente na cidade, transmitindo a visibilidade da atividade médica como beneméritos cidadãos em oposição ao exercício "oculto" dos pajés e curandeiros. (FIGUEIREDO, 2006)

Massarani et al (2013) analisou a imprensa da época no artigo intitulado $A$ ciência nas paginas da Folha do Norte: um olhar ao longo de oito décadas com intuito de identificar e classificar as notícias referentes ao conhecimento científico, inclusive as profissões a que se associam, sendo que, "os assuntos relacionados com medicina e saúde foram os mais frequentes nas páginas do jornal" (MASSARANI, et al, 2013, p. 295).

Os jornais, Estado do Pará e A Província do Pará, também noticiaram acentuadas polêmicas relacionadas com a odontologia no período que antecedeu a criação da Escola Livre de Odontologia do Pará, como veremos no decorrer deste artigo. Aliás, o nosso objetivo é analisar essas notícias, interrogando se elas registraram disputas pelo monopólio da prática odontológica no cenário paraense e se essas disputas foram vinculadas aos propósitos de fundar uma escola de odontologia no Pará.

\section{As denúncias contra os dentistas práticos}

No dia 25 de agosto de 1911 foi estampada no jornal Estado do Pará, uma notícia denunciando a atividade dos "dentistas práticos". A denúncia inicialmente partiu de Rogério Alvarez, um suposto cliente do então dentista João de Deus da Costa. Na denúncia, o primeiro informa que este the havia extraído um dente, provocando uma fratura do maxilar.

O sr. Rogério Alvarez, residente á travessa Ruy Barbosa, 86-B, endereçou ontem ao sr. dr. Eloy Simões, chefe de polícia, uma petição queixando-se contra João de Deus da Costa, estabelecido com gabinete dentário á rua Nova de Sant'Anna, 65, denunciando-o ao mesmo tempo como incurso nos artigos 8 e 338 do Código Penal da República. Alega o sr. Alvarez haver João da Costa, há meses, por ocasião de Ihe extrair um dente, Ihe fraturado a tábua externa do maxilar superior direito, produzindo-Ihe a 
abertura do antro do Highmore 5 , resultando daí uma fistula. (ESTADO DO PARÁ. Sexta-feira, 25 de Agosto de 1911, p. 2).

Por conta do ocorrido, o denunciante solicitou que se fizesse exame de corpo de delito e averiguação do caso. E para que não houvesse dúvidas, quanto à denúncia, a notícia informava que o fato ocorrido com o paciente, teria sido testemunhado por três cirurgiões dentistas diplomados.

Fundamentando a sua queixa, o sr. Alvarez documenta o alegado com os testemunhos dos cirurgiões-dentistas Manoel de Britto Pontes, Carneiro de Leão e Luiz Gonzaga Pacheco, e termina solicitando o competente exame de corpo de delito e as demais diligências policiais que o caso exige. Iniciou os necessários inquéritos a respeito o dr. Morisson de Farias, $1^{\circ}$ prefeito. (ESTADO DO PARÁ. Sexta-feira, 25 de Agosto de 1911, p. 2).

Dois dias depois, apareceu uma notícia publicada em outro jornal, A Província do Pará, sem assinatura, em defesa de João de Deus. Trata-se de uma nota em apoio a este profissional, criticando as acusações que o mesmo vinha recebendo e enfatizando a suposta solidariedade que teria recebido de importantes famílias da sociedade local por conta das acusações injustas e malévolas, feitas por inimigos, contra a competência profissional de João de Deus.

O cirurgião dentista dr. João de Deus da Costa tem sido nestes dois últimos dias alvo de inequívocas provas de apreço e de solidariedade das mais gradas pessoas e famílias da sociedade belemense, pesarosas pelas injustificadas e malévolas acusações apresentadas por inimigos seus contra a sua honorabilidade e competência profissional. De vários de seus colegas tem também o dr. João de Deus recebido iguais demonstrações. (A PROVÍNCIA DO PARÁ, 27 de agosto de 1911, p. 2).

No dia 29 de agosto uma nova notícia, publicada no jornal Estado do Pará, com título "Dentista em apuros", informava sobre o andamento do processo movido por Rogério Alvarez, que como vimos nesse jornal, alguns dias antes havia denunciado o dentista João de Deus, por este ter deformado seu maxilar. O texto acrescenta ainda que após as diligências policiais, o acusado apresentou documentos, que segundo ele, comprovariam sua legitimidade para atuar como dentista, o que foi contestado pelo jornal, pois indicaria que embora tenha executado alguns trabalhos técnicos, esses eram primários, e mesmo assim, por não ter realizado exame, não teria se graduado.

Há dias noticiamos haver o sr. Rogério Alvarez apresentado á polícia uma queixa contra João de Deus da Costa, estabelecido com gabinete dentário á rua Nova de Sant'Anna, pelo fato deste tê-lo deformado, quando the extraía um dente. As diligências policiais, que ficaram conclusas ontem, estiveram a cargo do dr. Morisson de Faria, $1^{\circ}$ prefeito. A esta autoridade, João de Deus da Costa apresentou seus documentos, por meio dos quais estava exercendo a profissão dentária. Esses documentos, porém, não têm

\footnotetext{
${ }^{5}$ Em meados do século XVII, Nathaniel Highmore desenvolveu um estudo mais detalhado sobre o seio maxilar, no qual descreveu, em seu livro Corporis Humani Disquisitio Anatomica, as relações anatômicas do seio maxilar, demonstrando a proximidade dos alvéolos dentários com essa cavidade. O cirurgião e anatomista inglês denominou-o de "Antro de Highmore", epônimo que ficou consagrado até a atualidade (BATISTA, et al., 2011).
} 
validade alguma. Trata-se de um simples atestado passado pelo prático dentista Antonio Corrêa Lima e outro de um certificado da escola nacional de dentisteria, de New York, datado de 22 de março de 1907. Este certificado diz que "João de Deus da Costa, como estudante especial, executou alguns trabalhos técnicos exigidos no curso primário, não tendo exame algum, por isso que não foi candidato ao grau". (ESTADO DO PARÁ, 29 de Agosto de 1911, p. 2).

A improcedência das praticas dentarias realizadas por João de Deus, dizia o jornal, era corroborada pela análise dos documentos apresentados por este. Análise que teria sido realizada por uma comissão formada por três cirurgiões, legitimados por diplomas obtidos em faculdades.

Estiveram a examinar esses documentos na primeira prefeitura, os cirurgiões-dentistas, diplomados em faculdades brasileiras, srs. Manoel de Britto Pontes, Carneiro de Leão e Ângelo Barra. Ficou, assim, provado que o sr. João de Deus da Costa não pode exercer a profissão de dentista. (ESTADO DO PARÁ, 29 de Agosto de 1911, p. 2).

Na mesma notícia os cirurgiões dentistas apresentaram ao redator do jornal, uma nota de repúdio contra um suposto apoio de alguns colegas ao então "dentista prático" denunciado, João de Deus. Entre os que assinaram a declaração, havia alguns futuros professores da Escola Livre de Odontologia do Pará, criada três anos após, como Magno e Silva, Alberto Pereira e João Amaral. Trata-se de uma declaração pela qual este apoio teria sido dado por portadores de "títulos científicos" legais e que, portanto, como havia sido comprovado, o dentista citado, "não passava de um charlatão".

Os abaixo assinados, cirurgiões-dentistas residentes nesta capital, deparando n'A Província do Pará de 27 do corrente uma local relativamente ao apoio prestado por diversos colegas ao cirurgiãodentista Dr. João de Deus da Costa, vêm, por meio desta declarar que jamais apoiaram e apoiarão pessoas que não são portadores de títulos científicos legais, como soe acontecer com o supracitado Dr. que não passa de um mero charlatão, como ficou provado com o atestado por ele apresentado á repartição de polícia. ${ }^{6}$. (ESTADO DO PARÁ, 29 de Agosto de 1911, p. 2).

No dia 1 de setembro de 1911, um novo noticiário informa que os cirurgiões dentistas se organizaram no sentido de estabelecer oposição a todos os praticantes ditos ilegais da arte dentária. Os "dentistas práticos" apareciam como profissionais cuja prática precisaria ser combatida, como percebemos no seguinte trecho em que mostra que houve uma reunião dos cirurgiões dentistas onde a finalidade foi levantar o número de profissionais, formados nas faculdades, atuantes em Belém, para que estes se organizassem oficialmente para combater aos que chamavam de charlatães.

No gabinete dentário do cirurgião-dentista sr. G. N. Carneiro de Leão, á travessa Frutuoso Guimarães, congregaram-se ontem, à tarde, em reunião

\footnotetext{
${ }^{6}$ Entre os cirurgiões dentistas que assinaram o documento estiveram J. N. Carneiro Leão, Manoel de Britto Pontes, Ângelo Barra, Argemiro Pinto, Luiz de Gonzaga Pacheco, Alberto Pereira, João Amaral, Antonio Borges, Magno e Silva e Abel da Costa.
} 
especial, os cirurgiões dentistas diplomados em faculdades brasileiras. Estiveram presentes os membros dessa classe, em grande número. $O$ fim da reunião foi tratar do levantamento da classe, estabelecendo oposição formal aos charlatães, sobre os quais chamarão a atenção do serviço sanitário do Estado. Resolveram também nomear uma comissão, afim de tratar desse assumpto com o sr. dr. governador do Estado. (ESTADO DO PARÁ, 1 de setembro de 1911, p. 1).

Os efeitos dessa reunião surgiram alguns dias depois, conforme mostra o jornal em 23 de setembro, informando sobre uma petição em que alguns cirurgiões dentistas cobravam providências das autoridades do Serviço Sanitário do Estado contra a atuação de pessoas que exerciam a profissão sem a devida comprovação de que tinham o título de cirurgião dentista. Nesta petição:

[...] o cirurgião dentista Argemiro Pinto e outros pedem providências no sentido de ser impedida a exploração que fazem com a odontologia os srs. João de Deus da Costa e outros, que intitulam-se cirurgiões dentistas, sem possuírem documentos comprobatórios de sua profissão. (ESTADO DO PARÁ, 23 de setembro de 1911, p. 2)

O "dentista prático" denunciado por exercício ilegal da prática dentária, João de Deus da Costa, revida essas acusações no artigo publicado no mesmo jornal Estado do Pará, em 21 de setembro de 1911, com o título de Explicação Necessária. O artigo apresentava argumentos a favor de sua prática como dentista, argumentando que o real motivo das denúncias contra ele, seria a sua vasta clientela, que deixava outros gabinetes dentários desertos. Ele afirma, ainda, que as denúncias feitas por clientes seriam parte do "plano vil e desleal" de outros profissionais para impedi-lo de exercer a prática odontológica e conduzir seus clientes para seus consultórios.

A aceitação com que felizmente me honram os meus conterrâneos e a numerosa frequência do meu gabinete cirúrgico dentário tem contra mim levantado o despeito de alguns colegas. Vários destes, julgando talvez conseguir encaminhar para os seus consultórios desertos, a minha clientela desde que possam privar-me da laboriosa e honesta atividade, para esse mesquinho fim vêm, de algum tempo, incansavelmente trabalhando. Para isso, não escolhem os condenáveis meios de executar o plano vil e desleal, lançando também em campo indivíduos fracos e inconscientes como instrumentos. Até hoje todos os manejos fracassaram porque tenho por mim o abono de minha conduta honesta contra a calúnia e manobras dos detratores e o direito sagrado de dedicar-me á carreira lícita que abracei. (ESTADO DO PARÁ, 21 de setembro de 1911 p. 3).

No mesmo artigo, João de Deus, defende a própria legitimidade para exercer a prática odontológica, afirmando que se aperfeiçoou durante longo tempo com os mestres, pelos quais se aprende verdadeiramente a prática da arte dentária. Para corroborar essa legitimidade, ele enfatiza, ainda, que havia se aperfeiçoado em uma das escolas consideradas mais importantes no campo da odontologia na época, a "National School of 
Dentistry" de "New York", e que por esse motivo, as acusações contra ele não tinham fundamento.

De minhas habilitações profissionais é prova suficiente o aumento incessante de clientes nas classes distintas da nossa sociedade. No trabalho assíduo, por longos anos, nos gabinetes dos mestres, que é aonde se pode verdadeiramente aprender a arte dentária, habilitei-me, indo depois aperfeiçoar-me, em New York, na National School of Dentistry. Este iníquo processo ultimo há de certamente cair por falta absoluta de base e por ser contrário aos mais sagrados direitos individuais, triunfando assim a minha causa, que é a causa da justiça. (ESTADO DO PARÁ, 21 de setembro de 1911 p. 3).

A legitimidade profissional de João de Deus torna a ser questionada na edição de 13 de novembro de 1911. O artigo apresentado por "Um admirador da justiça" rejeitava o argumento apresentado pelo denunciado, onde o mesmo dizia ter o titulo de cirurgião dentista obtido em uma escola estrangeira.

O Tribunal Correcional desta capital em 6 do corrente, proferiu nos autos crime em que é acusado - João de Deus da Costa, uma decisão que reputamos digna de ser lida e apreciada pelos entendidos. Em data de 8 de setembro do corrente ano, o sr. $3^{\circ}$ promotor público deu denúncia contra o dito João de Deus da Costa, pelos seguintes fatos: Desde alguns anos que o denunciado, dizendo possuir um titulo de cirurgião dentista passado por uma escola estrangeira - quando apenas tem uma certidão de que fez, como "estudante especial", na National School of Dentistry New-York, alguns trabalhos do curso primário, mas sem haver prestado exame nem recebido grau algum, montou nesta capital á rua Nova de Sant'Anna, casa n. 67 (sobrado) um gabinete dentário, onde dá consultas e pratica todos os atos concernentes á profissão de cirurgião-dentista, fazendo mesmo, pela imprensa diária, anúncios de seus trabalhos, tudo com o fim de conseguir dinheiro das pessoas que o procuram. (ESTADO DO PARÁ, 13 de novembro de 1911, p. 2).

A notícia ainda explica sobre o andamento do processo, onde João de Deus foi acusado de ter cometido o crime de estelionato. Por conta disso, o julgamento foi transferido para o Tribunal Superior de Justiça, visto que a função do Tribunal Correcional seria julgar apenas processos, sem júri, de causas criminais considerados de menor gravidade.

Intimado o réu e testemunhas iniciou-se o processo com todas as formalidades, e achando-se em termos de ser julgado, julgou-se o Tribunal Correcional incompetente para conhecer dos fatos articulados na denúncia, mandando que seja instaurado contra João de Deus da Costa novo processo perante o Tribunal do Júri, visto o crime cometido por ele

\footnotetext{
${ }^{7}$ Em 1926, William Gies publicou um estudo sobre a história da educação odontológica nos Estados Unidos e no Canadá, intitulado Dental education in the United States and Canadá: a report to the Carnegie foundation for the advancement of teaching. Neste estudo, aparece apenas a New York College of Dentistry, fundada em 1866, e desde junho de 1925 passou a ser Dental School of New York University (GIES, 1926, p. 42). Portanto, não existe nenhum registro relativo à National School of Dentistry of New York.
} 
observar ás disposições do art. 338 do código penal (estelionato). 0 dr. $1^{\circ}$ promotor apelou dessa decisão para o Tribunal Superior de Justiça. Belém, 12 de novembro de 1911. - "Um admirador da justiça" (ESTADO DO PARÁ, 13 de novembro de 1911, p. 2).

O personagem principal de toda a confusão envolvendo cirurgiões dentistas e os "práticos", João de Deus da Costa, figurava frequentemente nas ocorrências policiais. Desta vez, ele foi acusado por ameaçar de morte um homem cujo um membro de sua família havia sofrido abusos pelo denunciado, que the teria feito propostas obscenas. A notícia publicada no jornal Estado do Pará em 11 de julho de 1912, informa que "uma pessoa da família do Sr. Francisco Sotero, residente á avenida de São Jerônimo, 211, foi desrespeitado no gabinete dentário do curioso ${ }^{8}$ João de Deus da Costa" a quem procurou tomar uma satisfação, sendo recebido "com as maiores grosserias, prometendo assassiná-lo caso levasse o fato ao conhecimento dos jornais". Por conta disso, Francisco Sotero procurou a polícia e o denunciou mais uma vez.

“(...) Como é natural o sr. Sotero ficou justamente indignado pelo procedimento criminoso de João de Deus da Costa, não somente por ter abusado infamemente de uma das pessoas de sua família, fazendo-Ihe propostas indecorosas como ainda por ter procurado intimidá-lo com ameaças de morte, e por isso resolveu comparecer ontem á polícia, relatando o ocorrido". (ESTADO DO PARÁ, 11 de julho de 1912, p. 2)

As noticias publicadas nos jornais não se restringiam a João de Deus. No dia 24 de dezembro de 1913, o jornal publicou uma notícia sobre uma ocorrência policial, cujo titulo é bastante sugestivo: "Dentista à martelo", onde um jovem ajudante de gabinete dentário resolveu montar seu próprio local de trabalho, sendo, então, acusado de exercício ilegal da odontologia.

Gabriel Esperante entendeu agora de ser dentista e, como tal, principiou a "desmontar" a boca da humanidade. Arranjara ele um quarto à rua da Indústria, esquina da avenida 15 de Agosto, para onde conduzia as vítimas que deviam ser sacrificadas. Esperante fora lavador de pratos em hotéis, tendo mais tarde passado a criado de gabinete dentário. Foi, então, que achou que também poderia ser dentista. Inúmeras são as vítimas que the caíram nas unhas e que, a esta hora, com as bocas deformadas, não cessam de maldizê-lo. A polícia, tendo, ontem, conhecimento das proezas dentárias do novo cirurgião, mandou buscá-lo, recolhendo-o ao xadrez. (ESTADO DO PARÁ, 24 de dezembro de 1913, p. 2)

Alguns anos depois, ainda nesta década, Gabriel se matriculou no curso da Escola de Odontologia, o que mostra que a exigência do diploma, para o exercício da odontologia, em uma escola especializada estava surtindo efeito. Depois de várias tentativas de ingresso, o investigado Gabriel Esperante conseguiu entrar no curso da Escola Livre de Odontologia do Pará em 1918. Gabriel Esperante era um jovem de naturalidade espanhola, que entrou

\footnotetext{
8 As expressões, curioso e charlatão, eram muito utilizadas no século XIX e no início do XX, e eram caracterizadas pela forte conotação pejorativa. Muitos curandeiros eram denominados curiosos e charlatães, sobretudo por parte dos representantes do saber médico institucionalizado. (FIGUEIREDO, 2008, p. 132).
} 
na Escola de Odontologia em 1917 como aluno ouvinte, prestando exame de admissão no ano seguinte?.

A polêmica envolvendo dentistas diplomados e "práticos", sobre o monopólio do exercício da profissão da odontologia, que existiam em varias localidades fora do Pará, tais como nos Estados Unidos e na Argentina, apontada por alguns autores (CARVALHO, 2006; SCHAPIRA, 2003), também se observa na Amazônia. Como vimos anteriormente, a partir de 1911, vários artigos foram publicados na imprensa diária, onde podemos observar a presença de uma acentuada polêmica sobre a prática odontológica.

As notícias favoráveis aos que possuíam formação acadêmica exigiam a proibição da prática odontológica àqueles que não tivessem essa formação. Defendiam a ideia de que só os diplomados deviam deter o monopólio da pratica da odontologia e acusavam alguns "práticos" de exercício ilegal.

Algumas notas eram dirigidas para a defesa dessas acusações. Estas, entretanto, não reivindicavam que a odontologia devesse ser praticada pelos não diplomados e sim que estavam sendo injustas com aqueles acusados de não possuir legitimidade para realizar os serviços dentários. Como vimos anteriormente, isso ocorreu no caso em que há uma defesa de João de Deus. Ela o defendia da acusação de não possuir diplomação exigida para exercer a profissão, afirmando que ele teria um certificado de cirurgião dentista obtido em uma escola de Nova Iorque.

Como se pode ver por essas notícias, a exigência do diploma não era contestada por nenhuma notícia, o que mostra que neste momento não havia mais condições favoráveis para defender exercício da profissão de cirurgião dentista sem a posse do diploma de formação em curso superior. Além disso, elas mostravam que nesse momento os cirurgiões dentista se reuniram para pressionar as autoridades para que estas tomem providências contra os praticantes ilegais da odontologia.

\section{Pela odontologia: a valorização do saber científico em oposição aos saberes dos "práticos".}

Os ataques contra os dentistas práticos também estiveram presente no artigo publicado por Julio Muniz, cirurgião dentista que se tornou professor das cadeiras de Prótese e Técnica Odontológica da Escola Livre de Odontologia. O texto de Muniz, publicado no jornal Estado do Pará em 14 de fevereiro de 1914, faz uma clara demonstração de defesa de uma prática odontológica realizada pelos cirurgiões dentistas, a qual seria científica, e por outro lado, apresenta varias tentativas de desqualificar a prática dos outros praticantes, aos quais chamava de sacamuelas, pseudodentistas, charlatães, etc.

O cirurgião dentista inicia seu texto mencionando uma representação movida pelos cirurgiões dentistas estabelecidos em Belém enviada para o governador do Estado, Enéas Martins, que parece estar relacionado ao movimento desencadeado em 1911, citado anteriormente, onde os cirurgiões dentistas se organizaram no sentido de lutar contra os "charlatães".

\footnotetext{
${ }^{9}$ ESCOLA LIVRE DE ODONTOLOGIA DO PARÁ, Termo de abertura de matricula, 10 de março de 1917.
} 
"É nobre e muito digna a atitude assumida pelos seus distintos colegas, signatários da representação apresentada ao exmo. sr. dr. Enéas Martins, no intuito, muito e muito louvável, de protestar perante s. exc. contra o exercício ilegal que, da profissão de cirurgião dentista, fazem, em Belém, certos indivíduos sem escrúpulos". (MUNIZ, 1914)

Muniz advogava em favor dos cirurgiões dentistas, a quem, no seu entendimento, seria de direito ter todos os privilégios sobre a prática odontológica, pois haviam passado por formação na faculdade, o que exigia "esforço e abnegação" para conseguir obter a base cientifica necessária para esta prática. Ele afirma que nos cursos de cirurgia dentária das faculdades, passava-se por uma formação "onde o ensino das diversas matérias que o constituem, é teórico e prático". Assim, ele enfatiza a relação entre a teoria e a prática no ensino da odontologia, pois "a par da imprescindível teoria científica, base sólida sem a qual não há prática imaginável que subsista, ensina-se e faz-se, ali, a prática necessária e correlata com a teoria aprendida e estudada". (MUNIZ, 1914).

O autor afirma ainda que nos cursos de cirurgia dentária, a teoria científica é imprescindível e deve estar relacionada com a prática. A odontologia, tal como a que era ensinada nas faculdades e escolas de formação de dentistas, devia enfatizar essa relação, visto que, essa, já era a prática em vigor em outras escolas congêneres.

Para reafirmar essas ideias, ele usa como exemplo a Faculdade de Medicina da Bahia, onde se diplomou. Nessa Faculdade, "as aulas de Anatomia, Histologia, Prótese, Higiene e Clínica Dentária", seriam quase, exclusivamente, práticas, onde os estudantes fortaleceriam "seus conhecimentos teóricos e científicos, na prática das mesmas matérias, teoricamente explicadas". Assinala, ainda, que o mesmo acontecia "nas demais Faculdades Médicas e Escola Dentárias do mundo" (MUNIZ, 1914).

Entre os argumentos para convencer os leitores (ou possíveis clientes), o cirurgião dentista, reivindica o direito de exercer exclusivamente a profissão, e destaca que "além do esforço e da abnegação que o estudante ou acadêmico necessita para formar-se, e fazer jus a um diploma honroso e merecedor", havia também, "o tempo gasto, o capital expendido, e a responsabilidade adquirida". Por isso, para Muniz não seria justo que um indivíduo sem importância alguma, um "quidam", recebesse os privilégios que, por direito, deviam ser dados apenas aos cirurgiões dentistas.

É justo, pois, depois disso, que um "quidam" qualquer, encostado e fortalecido numa "pratica" duvidosa, sem os recursos e conhecimentos duma base científica solida e necessária, venha, na vida prática, por inconsciência ou "avacalhamento", apresentar-se a uma clientela e sociedade, exigindo ou recebendo delas, as regalias e privilégios que só devem ser dados ou dispensados a quem os merece, de direito e de fato? (MUNIZ, 1914).

É importante observar que Muniz utilizou vários adjetivos para desqualificar os "dentistas práticos" - quidam; pseudodentistas; etc. Mas o que se destaca é que ele chama a atenção para o fato de que os cirurgiões dentistas tinham formação científica e que, portanto, não deviam ser confundidos com os pseudodentistas.

E que "prática" é essa que eles - os pseudodentistas - arrogam como defesa para seu ilegal exercício? É a prática nossa, adquirida e feita sob os olhos e cuidados de mestres peritos e competentes, e dirigida no sentido científico que só a teoria nos dá? Não, nunca! (MUNIZ, 1914). 
Sobre essa questão da prática adquirida pelos "dentistas práticos", Muniz orienta a sua crítica não somente à falta de responsabilidade dos pseudodentistas, mas também acusa a ignorância dos clientes que os procuravam. Esta seria "uma 'prática' adquirida, inconscientemente, á custa de 'martírios' e 'experiências' feitas nos clientes - pobres clientes! - que a boa fé e a ignorância levam, casual e infelizmente, até eles!". Desse modo, segundo Muniz, aquele protesto tornava-se também humanitário, haja vista que seria "a favor daquela clientela, vil e indignamente espoliada e explorada", que se levantava, da mesma forma que ele, Muniz, fazia, com a finalidade de defendê-la.

O discurso mostra que a prática dos diplomados não era socialmente aceita, e entre os motivos, incluía-se a presença dos práticos, por isso a campanha expressava preocupação com o "saneamento e expurgo" do que contribuía para o descrédito da profissão. Desse modo, o protesto contra os sacamuelas se tornava um dever moral e profissional, em nome da legitimação de um espaço de atuação profissional em que somente os diplomados pudessem ter o monopólio da prática odontológica.

Aquele protesto é um dever, é uma obrigação profissional e moral. E nenhum dos dignos signatários dele (nem eu, tão pouco, que, deste modo me manifesto solidário com eles) nenhum deles seria digno do diploma que têm se não tomasse a peito esta campanha de saneamento e expurgo, daquilo que concorre, há muito tempo, para o descrédito em que, infelizmente, vive a profissão de cirurgião-dentista, em nosso meio! (MUNIZ, 1914).

Evidentemente, isso mostra que havia um descrédito pairando sobre a imagem do cirurgião dentista, na cidade de Belém. De acordo com o trecho do discurso, a seguir, podemos observar que as pessoas não faziam distinção entre diplomado e dentista prático. Havia, no discurso do cirurgião dentista, o desejo de se livrar dos apelidos alcunhados por parte da população aos cirurgiões dentistas, que não os distinguiam dos demais praticantes. Observa-se o uso de adjetivos que visava desqualificar os "práticos" atribuindo a eles uma imagem de pessoas maldosas e desonradas. Em contrapartida, os cirurgiões dentistas aparecem como praticantes de uma profissão, que além de científica seria também nobre e humanitária.

Embora tarde, é tempo de alijarmos de nós, dando-os a quem os merece, esses estúpidos e injustos epítetos, que, por causa desses charlatães, o vulgo nos atirava, de "barbeiros" e "sacamuelas"! Só um ignorante do que seja a Ciência Odontológica, neste século, da Luz, e do progresso em que vivemos, é que ainda cognominará, com aqueles labéus ultrajantes e ferinos, por serem mesquinhos e indignos, todos aqueles que exercem esta profissão humanitária, nobre e mui digna, que é a cirurgia dentária! (MUNIZ, 1914).

Essa falta de distinção entre os profissionais diplomados e os não diplomados, apontada no texto, estaria com os dias contados, pois seria tempo de distinguir os cirurgiões dentistas dos sacamuelas. Muniz acreditava que a falta de conhecimento e a crença contribuía para que as pessoas procurassem os "práticos" ao invés do cirurgião dentista. Havia um engano por parte dos clientes, supondo serem dentistas diplomados, ou até mesmo por acreditarem que os charlatães podiam curá-los.

É tempo, pois, de distinguirmos. Há, em Belém, cirurgiões-dentistas e "sacamuelas"! O menor bom senso estava - e está a dizer - a quem 
precisava - e precisar - de tratamentos bucais ou dentários, qual deveria ou deve - ser daqueles, o procurado. Acontece, porém, que muitos clientes procuram, por os suporem, certamente, dentistas, ou mesmo por fé e crença (que péssima sugestão perigosa!) justamente esses "práticos" em "sacar-muelas"! (MUNIZ, 1914).

Os argumentos que procuravam fundamentar a prática dos formados, valorizando suas atividades e desqualificando as dos outros pretendiam estabelecer um distanciamento entre os dois grupos de praticantes. Uma das características usadas pelo cirurgião dentista para valorizar a odontologia era mostrar sua cientificidade (ou dizer que ela era científica) através das disciplinas que constituíam os cursos, o que a tornaria científica. Isso diferenciava a odontologia, do saber da arte dentária dos "práticos". Para Muniz o saber odontológico ia muito além de saber "arrancar dente". Era preciso ter conhecimento da Terapêutica Dentária para saber tratá-los, mantendo-os conservados, o que não estava ao alcance do conhecimento dos "práticos".

\begin{abstract}
"Sacamuelas"! "Arrancador de dentes"! E é nisto que se funda o "vasto" conhecimento daqueles que supõem que ser dentista consiste em "arrancar" dentes! E, no entanto, ao dentista, hoje, compete fazer, precisamente, o contrario... É um saber "conservar", "aproveitar" os dentes e tratá-los, que consiste um dos deveres da nossa profissão. E aí, é que esbarra e esbarrava a celebérrima "prática" dos tais pseudodentistas. E querem ver como se tornava fácil o desempenho da ilegal profissão deles? Aí vai: - o cliente queixava-se que lhe doía um dente? "Arrancavase"! Um dente estava muito cariado e demandava um tratamento clínico ou protético, que "eles" não sabiam fazer? "Arrancava-se"! (MUNIZ, 1914).
\end{abstract}

No discurso de Muniz se percebe uma tentativa de virar o jogo contra os práticos, atribuindo a eles o apelido que as pessoas comuns haviam empregado também aos diplomados. Com isso ele tentava estabelecer algumas diferenças, apontando quem eram os verdadeiros dentistas e os farsantes sacamuelas.

E é claro que a "Terapêutica Dentária" assim compreendida e exercida, só podia levar o vulgo a dizer - "mas isto não é um dentista... é um "sacamuela"! E tinham razão. Porque esses srs. que se dizem dentistas e que, ali estão, alguns até de consultório aberto não são outra coisa. São esses os "sacamuelas". (MUNIZ, 1914).

A imagem do cirurgião dentista, na visão de Muniz, é aquela do benfeitor da humanidade, que "desinteressadamente", teriam a responsabilidade social de mostrar as pessoas o risco que estavam sofrendo ao procurarem um dentista que não fosse diplomado, já que o governo não o faria.

A quem, em consciência e não por interesse, competia, mostrar á esses clientes ludibriados, o erro perigoso e grave que faziam? A quem competia abrir e encetar uma campanha nobre e utilitária, contra esses charlatães audaciosos, desde que a incúria ou a criminosa e inerte tolerância do governo o não fazia, como era o seu dever? A nós, que somos cirurgiões-dentistas, diplomados por Faculdades Nacionais, legalmente reconhecidas, e que temos responsabilidade legal, portanto, nos nossos conscientes trabalhos profissionais. (MUNIZ, 1914). 
Segundo Muniz, o cirurgião dentista moderno que não tivesse a par das pesquisas contemporâneas na área médica ou odontológica não estaria apito a lidar com doenças cujo efeito provocaria reações na anatomia bucal ou dentária, e citou como exemplo, a Albuminúria e o ácido úrico que provocariam "negridões" (equimoses) nos dentes, odontalgias, etc. Nesse caso, ele enfatiza que "o cirurgião-dentista 'verdadeiro', que sabe e conhece a sua profissão", indicaria "ao seu cliente um médico especialista daqueles casos, deixando para depois do tratamento médico, o tratamento odontológico, que lhe compete". Por outro lado, um dentista prático faria diferente, pois ele afirmava que:

[...] um "sacamuela" faria isso mais sumariamente: - "arrancava" o dente natural (que nenhum dente artificial substitui vantajosamente, pois compreende-se, facilmente, que um dente artificial não vale um dente "vivo") "arrancava", dizia eu, o dente natural enegrecido, para colocar em seu lugar um outro... artificialmente branco!!! Hão de concordar, leitores meus, que é extremamente fácil, pois não é? São uns pândegos estes "sacamuelas. (MUNIZ, 1914).

Depois de exemplificar como a odontologia agiria em caso de doenças específicas citadas anteriormente, Julio Muniz questiona se ainda haveria quem julgasse a "Odontologia uma Ciência de "arrancar" dentes?". E para valorizar ainda mais a odontologia como um campo de conhecimento científico, dizia o cirurgião dentista, que "até em Medicina Legal os dentistas prestam bons serviços", citando o exemplo que Subirana Matta, um "ilustre e distinto cirurgião-dentista argentino", havia relatado em um livro, o que classificou como "um caso curioso e interessante". Relatava ele, que:

Numa rua qualquer, em uma cidade italiana a polícia encontrou, certo dia, um cadáver. Tratava-se de um crime; e não foi possível identificar o morto. Um dentista daquela cidade lembrou-se, nessa ocasião, ir á "morgue", e pediu, á autoridade competente, licença para examinar a boca do cadáver! $E$, examinando-a, encontrou, num dos molares, uma obturação á ouro, e, num dos caninos, uma restauração, também, á ouro. E, ele, o dentista, que usava nos seus trabalhos clínicos e protéticos, o sistema, hoje, geralmente, adotado, dos "fixos", verificando-os, reconheceu no indivíduo da "morgue", um seu antigo cliente! Restabeleceu-se a identidade dele, pois a "fixa" dava o seu nome, etc., e, assim, de corolário em corolário, e de averiguação em averiguação, a polícia conseguiu prender o assassino... E então? Que tal saiu a Odontologia, hein, senhores, que consideram os dentistas verdadeiros como "sacamuelas"? Admirável, não é verdade? Pois a Odontologia é isto, senhores meus, uma ciência, uma arte, um sacerdócio! (MUNIZ, 1914).

O que foi visto até o momento, mostra que houve uma pressão, por parte dos cirurgiões dentistas, junto às autoridades no intuito de se estabelecer medidas punitivas contra os praticantes ilegais dos serviços dentários. Isso nos leva a entender que o objetivo principal dos diplomados era tornarem-se vitoriosos na campanha contra os sacamuelas pelo monopólio dessa prática na região. De acordo com o discurso de Muniz, havia uma certeza de que isso ocorreria, por considerar que a causa era "justa e reivindicadora", mas o que garantiria essa certeza era o fato de o governo ter cassado a licença para clinicar de um médico português pelo motivo de não ter sido registrado por uma faculdade brasileira, conforme a exigência da lei. 


\section{Considerações}

Neste artigo, pudemos observar que o jornal A Província do Pará e, sobretudo, o Estado do Pará noticiaram acentuadas polêmicas sobre o direito de praticar a odontologia, entre os profissionais que atuavam em Belém. Essas notícias foram publicadas nos jornais no período situado entre 1911 e 1914, ou seja, nos anos imediatamente antecedentes a criação da Escola Livre de Odontologia do Pará em 1914. Por essas notícias pudemos constatar que os cirurgiões dentistas se reuniram no sentido de pressionar as autoridades para estabelecer a legitimidade sobre as práticas odontológicas na região. Essas disputas envolveram denúncias contra o exercício da odontologia por parte dos dentistas práticos. As notícias a favor dos diplomados valorizavam as atividades realizadas por estes, desqualificando as dos demais, com o intuito de desclassificar as práticas odontológicas realizadas por estes.

As notícias dos jornais manifestam a luta dos profissionais diplomados, para garantir a valorização das próprias práticas odontológicas na sociedade da época. E ainda, o empenho pela necessidade de legitimação de um espaço de atuação profissional em que somente os que possuíssem diplomas pudessem ter o direito de exercer suas atividades. Para isso, houve a produção e veiculação pela imprensa, de um "personagem desviante", o charlatão, "sacamuelas", adjetivado pela irresponsabilidade, desonra, maleficência, para o qual os cirurgiões dentistas diplomados exigiam a repressão do Estado. Foi nesse contexto que surgiu a Escola Livre de Odontologia, que tinha o propósito de formar profissionais nesse campo de conhecimento para atuar na província do Pará.

\section{Referências}

A PROVÍNCIA DO PARÁ, Edição de Domingo, 27 de agosto de 1911.

BATISTA, P. S.; ROSÁRIO JUNIOR, A. F.; WICHNIESKI, C. Contribuição para o estudo do seio maxilar. Revista Portuguesa de Estomatologia, Medicina Dentária e Cirurgia Maxilofacial. 52 (4): 235-239. 2011.

CARVALHO, Cristiana Leite. A transformação no mercado de serviços odontológicos e as disputas pelo monopólio da prática odontológica no século XIX. História, Ciências, Saúde Manguinhos, v. 13, n. 1, p. 55-76, jan.-mar. 2006.

DAOU, Ana Maria. A Belle-Époque Amazônica. Rio de Janeiro: Jorge Zahar Editora, 2000.

EDLER, Flávio Coelho. A medicina no Brasil Imperial: clima, parasitas e patologia tropical. Rio de Janeiro: Editora FIOCRUZ, 2011.

ESCOLA LIVRE DE ODONTOLOGIA DO PARÁ, Termo de abertura de matricula, 10 de março de 1917.

ESTADO DO PARÁ. Edição de Sexta-feira, 25 de Agosto de 1911.

ESTADO DO PARÁ. Edição de Terça-feira, 29 de Agosto de 1911.

ESTADO DO PARÁ. Edição de sexta-feira, 1 de setembro de 1911.

ESTADO DO PARÁ. Edição de quarta-feira, 21 de setembro de 1911.

ESTADO DO PARÁ. Edição de sábado, 23 de setembro de 1911.

ESTADO DO PARÁ. Edição de segunda-feira, 13 de novembro de 1911. 
ESTADO DO PARÁ. Edição de quinta-feira, 11 de julho de 1912.

ESTADO DO PARÁ. Edição de quarta-feira, 24 de dezembro de 1913.

FigueIREDO, Aldrin. Esculápios bélicos: a Sociedade Médico-Cirúrgica do Pará e as efemérides cívicas da nação brasileira, 1914-1922. In: Documentos Culturais, n. 7. Belém: Conselho Estadual de Cultura, 2006. p. 41-50.

FIGUEIREDO, Betânia Gonçalves. A arte de curar: cirurgiões, médicos, boticários e curandeiros no século XIX em Minas Gerais. 2 ed. - Brasília, DF: Argvmentvm, 2008.

GIES, William. Dental education in the United States and Canada: a report to the Carnegie foundation for the advancement of teaching. Bulletin Number Nineteen. New York: The Carnegie Foundation for the Advancement of Teaching, 1926.

MASSARANI, Luisa; SEIXAS, Netília S. A.; CARVALHO, Vanessa B. A ciência nas paginas da Folha do Norte: um olhar ao longo de oito décadas. Revista Brasileira de História da Ciência, Rio de Janeiro, v. 6, n. 2, p. 283-300. Jul/dez, 2013.

MUNIZ, Julio. Pela Odontologia. In.: ESTADO DO PARÁ, Edição de sábado, 14 de fevereiro de 1914.

RODRIGUES, Silvio Ferreira. Senhores da cura: negociações e conflitos no diversificado universo da cura no extremo norte do Brasil, 1889-1919. Histórica - Revista Eletrônica do Arquivo Público do Estado de São Paulo, n 44, out. 2010.

SARGES, Maria de Nazaré. Belém: riquezas produzindo a Belle-Époque. Belém: Editora Paka-Tatu, 2000.

SCHAPIRA, Marta V. La odontología en Argentina: historia de una profesión subordinada. História, Ciências, Saúde. Manguinhos, vol. 10(3): 955-77, set.-dez. 2003. 